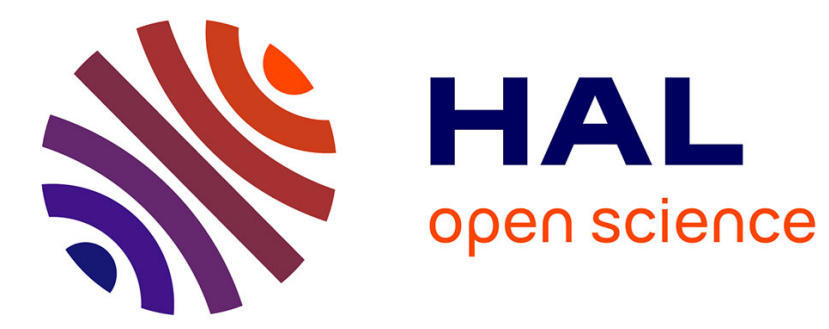

\title{
A new method of mounting stripper foils
}

K.R. Chapman

\section{- To cite this version:}

K.R. Chapman. A new method of mounting stripper foils. Revue de Physique Appliquée, 1977, 12 (10), pp.1547-1550. 10.1051/rphysap:0197700120100154700 . jpa-00244365

\section{HAL Id: jpa-00244365 https://hal.science/jpa-00244365}

Submitted on 1 Jan 1977

HAL is a multi-disciplinary open access archive for the deposit and dissemination of scientific research documents, whether they are published or not. The documents may come from teaching and research institutions in France or abroad, or from public or private research centers.
L'archive ouverte pluridisciplinaire HAL, est destinée au dépôt et à la diffusion de documents scientifiques de niveau recherche, publiés ou non, émanant des établissements d'enseignement et de recherche français ou étrangers, des laboratoires publics ou privés. 


\title{
A NEW METHOD OF MOUNTING STRIPPER FOILS (*)
}

\author{
K. R. CHAPMAN \\ Department of Physics, Florida State University, Tallahassee, Florida 32306, U.S.A.
}

\begin{abstract}
Résumé. - Une méthode est proposée pour le montage des feuilles d'épluchage de charge utilisant une grille de tungstène à haute transmission. Cela permet de subdiviser la feuille en un grand nombre de feuilles indépendantes, le mauvais fonctionnement de l'une d'elles n'affecte pas les autres. Il est donc possible d'utiliser une grande feuille que l'on déplace dans le faisceau afin de prolonger sa durée d'utilisation. Des résultats sont décrits ainsi qu'un mécanisme prototype pour l'exploitation de ce concept.
\end{abstract}

\begin{abstract}
A method of mounting stripper foils is proposed using a high transmission tungsten grid. This enables the foil to be subdivided into a large number of independent foils, failure of any one of which does not effect the rest. It is thus possible to use a large foil moved across the beam to obtain a very long life. The results are shown and a prototype mechanism to exploit this concept is described.
\end{abstract}

1. Introduction. - With the advent of ever larger electrostatic accelerators the problems associated with terminal stripping become a serious limiting factor in the performance of such installations. Gas stripping does not yield the high charge states required and foils do not have an acceptable life time. Considerable effort has been devoted to this problem and some limited success obtained using foils mounted slack or heated [1] and using unconventional gases and vapours [2]. The final result has, however, inevitably been a compromise, frequently using a gas as a first stripper, accepting the lower charge state and a second foil stripper part way down the high energy column where its life time is increased considerably. Proposals have also been made to use fluid strippers but at best much development work remains to be done before this can be considered a practical solution.

Grids are routinely used in accelerator technology to obtain the desired electrostatic profiles in large aperture lenses. These grids are normally made of tungsten either woven or electrochemically etched. Such grids are readily obtained with transmissions of $85-90 \%$ or higher and it is proposed to use a tungsten grid of this type to produce a stripper foil having a long life.

A foil fails due either to rupture or an increase in thickness rendering it unusable as a result of the increase in multiple scattering. This latter effect is reduced by use of clean high vacuum techniques but not eliminated. There is evidence [3] that the thicke-

$\left(^{*}\right)$ This work was supported in part by the National Science Foundation, Grants Numbers NSF-GU-2612 and NSF-PHY7503767. ning in the area of beam impact is at least partially due to migration of material from the surrounding foil into this area. Now if a single large foil can be subdivided into a large number of very small foils and these sub-foils made to act independently the potential for long life exists as a rupture will be limited to a small part of a foil. It is quite well known that frequently the transmitted beam through an accelerator can be increased by moving a stripper foil, that has been run for sometime, off center. This exposes a fresh thin section of foil to the beam, unfortunately, however, the initial increase in thickness and radiation damage frequently leads to shrinkage [4] and rupture.

2. Proposed mounting method. - The object of this method is to mount a large, thin carbon foil over a high transmission grid taking care to insure that the foil is bonded to the grid so that failure of the foil covering one aperture will be limited to that aperture.

Traditional stripper foils are carbon $\simeq 5 \mu \mathrm{g} / \mathrm{cm}^{2}$ thick and are produced by evaporation onto a glass slide coated with release agent. This film is then floated off and picked up on a stripper foil frame on which has previously been mounted a formvar film. Basically the same technique is used, the carbon is evaporated onto a substrate coated with release agent. Glass can be used for the substrate but thin chromium plated stainless steel, as used for photographic glazing, appears to be more convenient. The tungsten grid is bonded to the frame using low vapour pressure epoxy and the floated film is picked up on this. A formvar film can again be used but may not be desirable. The much smaller apertures of the grid mean that the carbon film is self supporting without 
backing and the formvar appears to give a less satisfactory bond of the carbon to the tungsten. The whole concept depends on this bond to render adjacent apertures independent. We have achieved very satisfactory bonds by spraying a very thin coating of vacuum grease onto the grid before mounting the carbon. This is an effective but probably not ideal method and other techniques are obviously possible using perhaps an epoxy dissolved in solvent to obtain a very fine coating. Such a method would be more acceptable on an accelerator using ultrahigh vacuum systems. It might be possible to evaporate directly onto the grid using a backing such as formvar on the other side of the grid but heating problems would have to be solved. With the use of vacuum grease, this will crack to carbon at least in the region heated by the beam and so a clean high temperature bond is achieved.

The grid material can be woven or electrochemically etched and the latter although rather more expensive is preferable as it has much greater rigidity than its woven counterpart and presents a flat surface for the mounting of the carbon. It is also possible to obtain this with a solid frame around the etched area with obvious advantages in rigidity and mounting possibilities.

3. Applications. - This method of mounting may be expected to give some increase in foil life even when used utilizing standard foil frames. The mechanical strength of the foil is increased considerably and even with some apertures ruptured a useful beam may still be obtained from the remainder. There is also a heating effect. The grid only intercepts perhaps $5 \%$ of the beam but this can represent a nonnegligible wattage. ( $5 \%$ of $10 \mu \mathrm{A}$ at $10 \mathrm{MV}=5$ watts). This heat is lost partially by conduction but principally by radiation so the area of the foil hit by the beam and in its vicinity will run hot and there is evidence that under some conditions this will enhance foil life time $[1,2]$. The real advantages are, however, only obtained by use of large foils. If beam conditions are such that a stationary foil will last 10 minutes and if we assume that the beam at the foil is $5 \mathrm{~mm}$ in diameter then to maintain transmission the foil would need to be translated at a rate of $3 \mathrm{~cm} /$ hour; a foil $7.5 \mathrm{~cm}$ square if scanned in a raster across the beam would last 36 hours. With a mechanism that would hold 50 foils, a foil load used at this rate would last $21 / 2$ months.

4. Results. - The first test we made was the obvious one. We mounted a small number of foils on standard frames using a woven grid backing with $\simeq 90 \%$ transmission and made these part of a regular load in the accelerator. We did this as a quick and simple test which would show at once if some unforseen effect existed that would render the procedure inoperable. We were pleased but not surprised to observe transmissions that were, within experimental error, identical to that from regular foils. A $10 \%$ loss would have been difficult to observe due to foil variations and the poor statistics imposed by the smaller number of foils. When the stripper was reloaded it was observed that no detectable damage had occurred to the grids although oxygen beams of $5 \mu \mathrm{A}$ had been run at a terminal potential of $\simeq 9 \mathrm{MV}$. One might thus expect to be able to use a grid many times, just reloading carbon, before it needed replacement. It was also noticed that the gridded foils had generally survived better than their ungridded counterparts.

Backed by this evidence we proceeded to tests with a moving foil. An assembly was built which allowed a long narrow foil to be moved across the beam at a constant speed (Fig. 1). The speed used

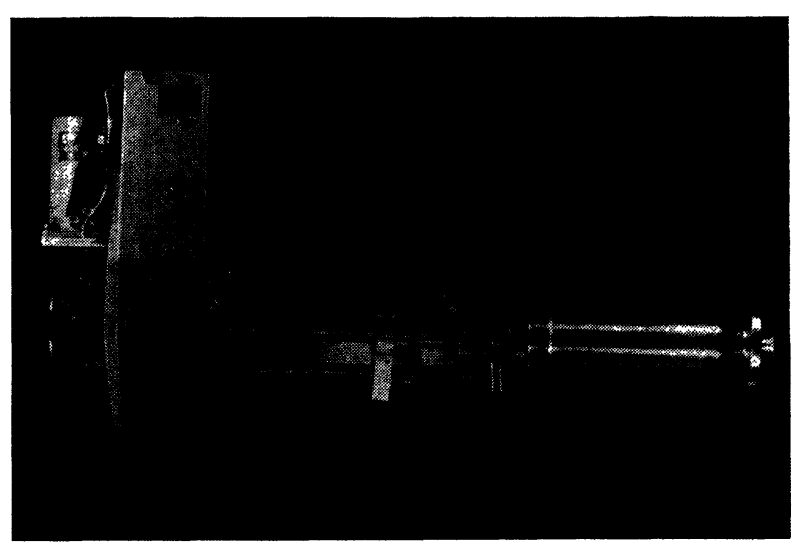

FIG. 1. - Mechanism to move foil across beam at a pre-determined rate.

being continuously variable over a considerable range by use of a stepping motor driven by a pulse generator. Grid backed foils were mounted over an aperture $1 \mathrm{~cm}$ wide by $20 \mathrm{~cm}$ long (Fig. 2) and bombarded by the external oxygen beam from the Florida State University Tandem accelerator, with $8.5 \mathrm{MV}$ on the terminal and $2 \mu \mathrm{A}$ of +6 charge state incident on the foil, it was translated at $2.5 \mathrm{~cm} /$ hour. The beam
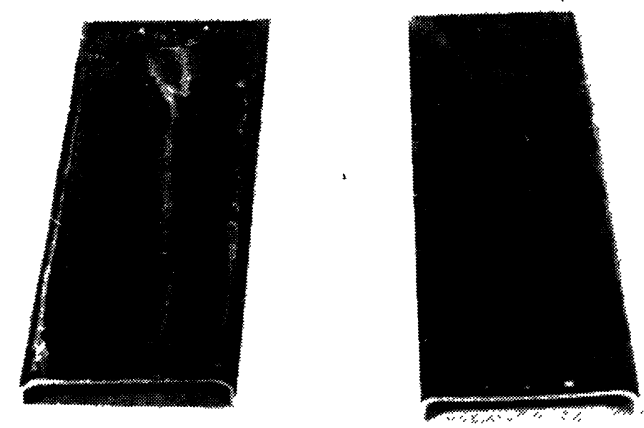

FIG. 2. - Foil holder with tungsten grid and a foil mounted for translational tests. 
spot could be seen hot on the foil but the carbon passed the beam undamaged. Even with the foil stationary the time necessary to destroy the foil was too long to enable meaningful results to be obtained in a reasonable time.

These test were therefore, transferred to the accelerator at the University of Florida in Gainesville. Here a nitrogen beam at $4 \mathrm{MV}$ is obtainable from their single ended machine. One run has been made using this beam and the results are most encouraging but not quantitative. The problem arising from the poor transmission of this installation for heavy ions around the analysing magnet. To obtain beams of 15$20 \mu \mathrm{A}$ of nitrogen the foil was mounted before this magnet and visually the foil could be seen to run red hot and the beam beyond the foil could be seen as a purple streak. Unfortunately the charge state distribution onto the foil and the effect of neutrals is not known, measured after the magnet the charge state distribution was $5: 1.4: 0.75$ between the $+1:+2$ : +3 charge states. Under these conditions a stationary foil failed in $\simeq 15$ minutes but by translating the foil a constant beam stripped in the foil could be analysed by the magnet. No damage to the grid was observed.

5. A foil mechanism. - Whilst these tests were proceeding a prototype mechanism was designed and its construction is now nearing completion (Fig. 3). It is not suggested that this is the only design possible or perhaps even the best but it illustrates a practical realization of this concept. It is designed for a horizontal accelerator but could as easily be designed for a vertical one.

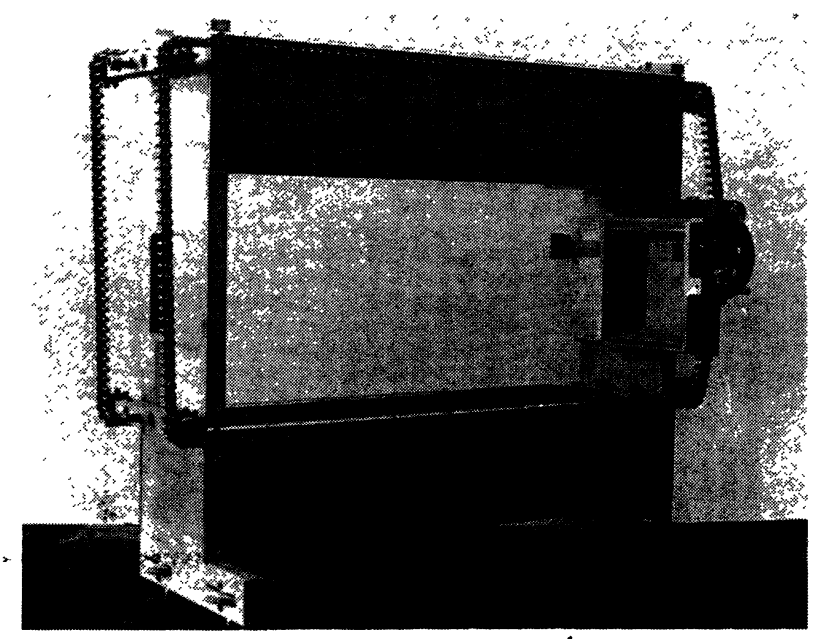

Fig. 3. - Prototype foil mechanism for use in tandem terminal. Foils can be seen in upper and lower magazines and also the chain pegs that control foil loading and unloading.

Some foils having a useful aperture of $7.5 \times 7.5 \mathrm{~cm}$ (Fig. 4) are held in an upper magazine. When required, a foil is moved to one end where it drops into a holder mounted on a cross slide. Here in the active position it is scanned across the beam in a raster in any required fashion and at any required speed. When this foil is exhausted it is dropped into a lower magazine and a new slide loaded. The transport of the slides being controlled by pegs mounted on a roller chain.

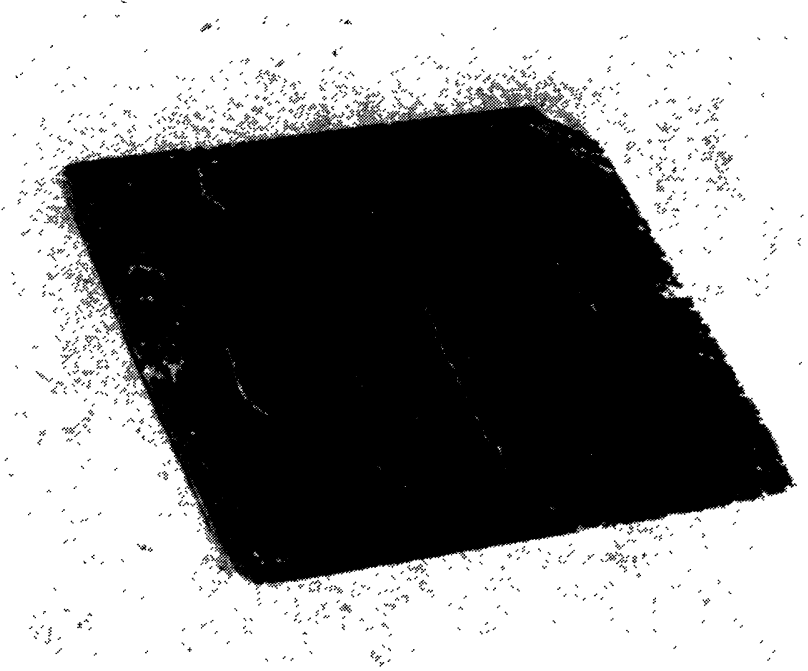

FIG. $4 .-7.5 \mathrm{~cm} \times 7.5 \mathrm{~cm}$ foil mounted in holder.

Initially the cross slides (Fig. 5) are arranged so that motion in one direction is controlled by a screw drive whilst that in the other direction is by use of a rack and pinnion. This enables the foil to be translated slowly across the beam using the screw and then

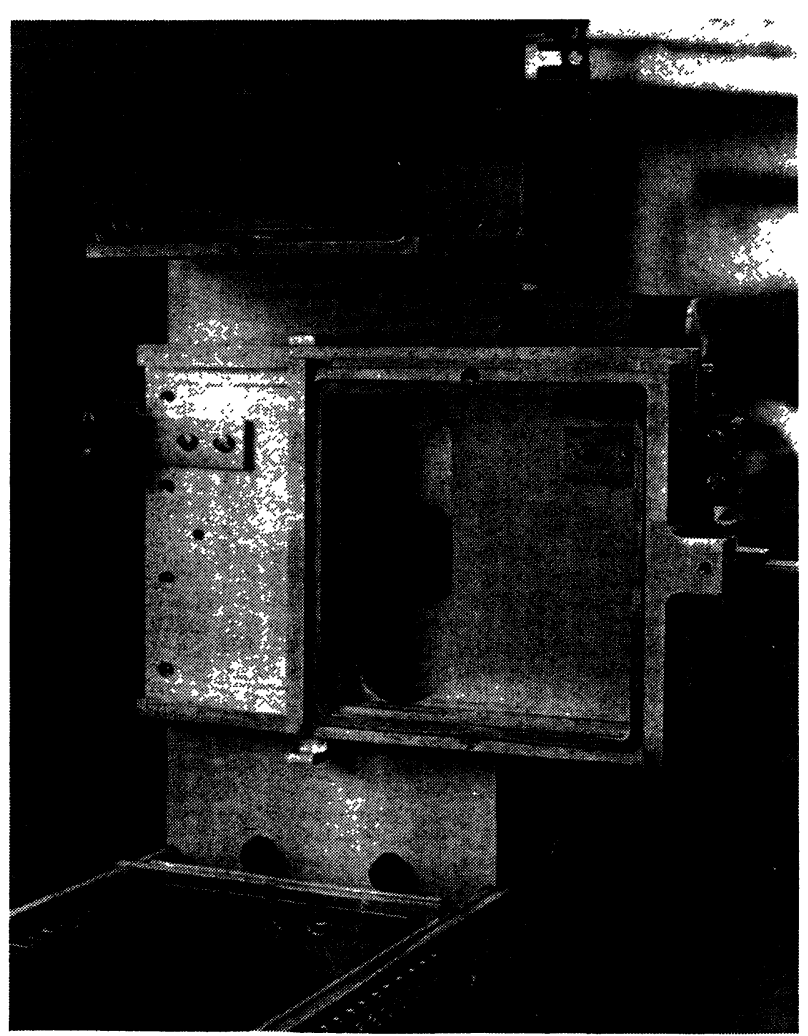

Fig. 5. - Close up of cross slides to scan foil across the beam in a raster. 
rapidly moved in a perpendicular direction using the rack and pinnion ready for a slow parallel scan back in the reverse direction.

Electrochemically etched grids can be obtained with almost any required number of wires per inch or any required wire thickness. This offers many possibilities as regards percentage transmission and individual aperture size. The possibility even existing that if in a high current, high energy installation, the life time of the grid itself should prove to be unacceptably short, then a grid could be used that did not intercept the beam. This would consist of a large number of apertures approximately the same size as the beam at the stripper and the beam would be stepped from aperture to aperture at a predetermined rate, every $7.5 \mathrm{~cm} \times 7.5 \mathrm{~cm}$ foil in effect becoming a series of perhaps 200 foils.

6. Future developments. - The mechanism will be completed and especially the scanning drives will be developed, the mechanical motions being brought into the vacuum box using magnetic drives. A suitable stripper box will be built to contain the stripper mechanism and the whole assembly will be mounted in the terminal of the FSU Tandem and tested.

Considerable development work remains to be done on a type of grid to be used and the best technique for mounting the foils. We can successfully mount foils but the method to give the best bond to the grid has to be determined, having regard to high vacuum requirements.

7. Conclusions. - A method is proposed which has proved most successful on initial tests and which offers promise of rendering foil stripping possible in situations where it has previously been impractical. Its possibilities being in large measure determined by the ingenuity of the mechanisms devised to exploit it.

Acknowledgements. - Thanks are due to those who have helped in the many aspects of this work especially $\mathrm{H}$. Abner who built the translational mechanism for the intital test, to B. Leonard for the production and mounting of the foils and to $G$. Velisek for construction of the prototype mechanism and his patience with the many changes that have been necessary.

\section{References}

[1] Yntema J. L., Nucl. Instrum. Methods 98 (1972) 379.

[2] Eastham D. E. and Joy T., Daresbury Prepint : DL/NSF/P 34 Nov. (1975).

[3] Henkel R. L., Proceedings of Daresbury Conference on Technology of Electrostatic Accelerators, 280 (1973).

[4] Whitmell D. S., et al. Proceedings of Daresbury Conference on Technology of Electrostatic Accelerators, 265 (1973). 